\title{
Simultaneous observations of ESF irregularities over Indian region using radar and GPS
}

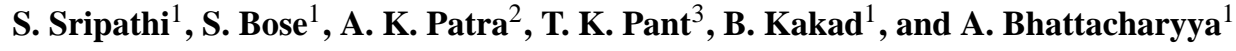 \\ ${ }^{1}$ Indian Institute of Geomagnetism, Navi Mumbai, India \\ ${ }^{2}$ National Atmospheric Research Laboratory, Gadanki, India \\ ${ }^{3}$ Space Physics Laboratory, VSSC, Trivandrum, India
}

Received: 7 November 2007 - Revised: 18 July 2008 - Accepted: 2 September 2008 - Published: 21 October 2008

\begin{abstract}
In this paper, we present simultaneous observations of temporal and spatial variability of total electron content (TEC) and GPS amplitude scintillations on L1 frequency $(1.575 \mathrm{GHz})$ during the time of equatorial spread $\mathrm{F}$ (ESF) while the MST radar (53 MHz) located at Gadanki $\left(13.5^{\circ} \mathrm{N}, 79.2^{\circ} \mathrm{E}\right.$, Dip latitude $\left.6.3^{\circ} \mathrm{N}\right)$, a low latitude station, made simultaneous observations. In particular, the latitudinal and longitudinal extent of TEC and L-band scintillations was studied in the Indian region for different types of ESF structures observed using the MST radar during the low solar activity period of 2004 and 2005. Simultaneous radar and GPS observations during severe ESF events in the pre-midnight hour reveal that significant GPS L band scintillations, depletions in TEC, and the double derivative of the TEC index (DROTI), which is a measure of fluctuations in TEC, obtained at low latitudes coincide with the appearance of radar echoes at Gadanki. As expected, when the irregularities reach higher altitudes as seen in the radar map during pre-midnight periods, strong scintillations on an L-band signal are observed at higher latitudes. Conversely, when radar echoes are confined to only lower altitudes, weak scintillations are found and their latitudinal extent is small. During magnetically quiet periods, we have recorded plume type radar echoes during a post-midnight period that is devoid of L-band scintillations. Using spectral slopes and crosscorrelation index of the VHF scintillation observations, we suggest that these irregularities could be "dead" or "fossil" bubbles which are just drifting in from west. This scenario is consistent with the observations where suppression of prereversal enhancement (PRE) in the eastward electric field is indicated by ionosonde observations of the height of equatorial $\mathrm{F}$ layer and also occurrence of low spectral width in the radar observations relative to pre-midnight period. However, absence of L-band scintillations during post-midnight
\end{abstract}

Correspondence to: S. Sripathi

(ssripathi@ rediffmail.com) event, when radar observed plume like structures and scintillations were recorded on VHF band, raises questions about the process of evolution of the irregularities. A possible explanation is that whereas small scale $(\sim 3 \mathrm{~m})$ irregularities are generated through secondary waves that grow on the walls of $\mathrm{km}$ scale size irregularities, in this case evolution of the Rayleigh-Taylor instability itself did not extend to irregularities of scale sizes of a few hundred meters that produce scintillation on a L-band signal.

Keywords. Ionosphere (Equatorial ionosphere; Ionospheric irregularities)

\section{Introduction}

The Equatorial Spread F (ESF) irregularities in the nighttime $F$ region ionosphere have been extensively studied for the past several decades under varied space weather conditions (e.g. Fejer and Kelley, 1980; Ossakow, 1981; Kelley, 1989). The name "Equatorial Spread F" has come from ionogram observations of a spread in the range or frequency on some nights over equator (Booker and Wells, 1938). The ESF irregularities have a "spectrum" that contains various scale sizes ranging from a few centimeters to hundreds of kilometers and hence radio waves of different frequency bands are used to study different parts of the irregularity spectrum (e.g. Kelley, 1989). These plasma irregularities have been studied using ground-based coherent radars, optical airglow and ionospheric scintillation observations as well as in situ rocket and satellite observations over equatorial and low latitude locations (e.g. Mendillo and Baumgardner, 1982; Patra et al., 1997; Hysell and Burcham, 1998; Kil and Heelis, 1998; Kudeki and Bhattacharyya, 1999; Sinha et al., 1999; Bhattacharyya et al., 2001; Burke et al., 2004). Scintillations observed on UHF/VHF signals transmitted from a geostationary satellite and recorded using single ground receiver

Published by Copernicus Publications on behalf of the European Geosciences Union. 
system as well as spaced ground receiver systems are used to monitor the plasma irregularities (e.g. Su. Basu and Kelley, 1977; Yeh and Liu, 1982). In recent times, GPS signals have been used to derive Total Electron Content (TEC) and amplitude scintillations on L-band signal, which have been extensively used to study the ESF irregularities (e.g. Bhattacharyya et al., 2000; Valladares et al., 2004; Ramarao et al., 2006a, b). The importance of all these studies lies in the fact that these irregularities affect radio wave communication adversely and hence there is need to understand their generation and evolution and model them accurately.

The source mechanism for generation of the $F$ region plasma irregularities have been broadly understood in terms of growth of the generalized Raleigh-Taylor (R-T) instability on the bottomside of the post-sunset equatorial $\mathrm{F}$ region, where a heavy fluid is supported by a lighter fluid, which is a highly unstable equilibrium condition (e.g. Haerandel, 1974; Kelley, 1989; Sultan, 1996). According to this mechanism, if any small perturbation occurs on the bottomside of the post-sunset equatorial $\mathrm{F}$ region, this perturbation is amplified through a feedback mechanism and as a depleted plasma bubble penetrates into the topside ionosphere, small scale irregularities are generated. Since these plasma irregularities are highly field aligned, they are mapped also to higher latitudes as irregularities evolve non-linearly into the topside ionosphere (e.g. Whalen, 2002). Radar observations have shown good correlation between the height of $F$ layer and $\boldsymbol{E} \times \boldsymbol{B}$ drift and the height of the equatorial $\mathrm{F}$ layer has been found to be higher on the nights of spread F (Farley et al., 1970; Fejer et al., 1999). The key factors that control the generation and distribution of ESF irregularities under magnetically quiet periods have been identified to be the height of the post-sunset $F$ region and hence the pre-reversal enhancement (PRE) of the vertical drift of the equatorial $\mathrm{F}$ region plasma, longitudinal conductivity gradients, transequatorial winds, integrated flux tube conductivities and seed perturbation (e.g. Abdu, 2001). However, under magnetically active periods, it is necessary to first identify nascent equatorial plasma bubbles (EPBs) in order to associate their appearance with the reversal of the zonal electric field from westward to eastward (Bhattacharyya et al., 1989, 2002; Kakad et al., 2007). Studies indicate that a good correlation exists between the PRE and the location of the Appleton or equatorial ionization anomaly (EIA) with respect to the magnetic equator (Whalen, 2001; Valladares et al., 2001). Observations presented using ionosondes also suggest that density enhancement associated with EIA is seen at higher latitudes during the time of ESF (Raghavarao et al., 1988). Studies reveal that asymmetry (symmetry) in the equatorial ionization anomaly also suppresses (enhances) the growth of the plasma bubbles due to the role of meridional wind circulation (e.g. Devasia et al., 2002; Lee et al., 2005; Thampi et al., 2006). Recent satellite observations reveal that even atmospheric tides may control the growth of ESF irregularities (e.g. Immel et al., 2006).
It may be noted that while significant progress has been made in understanding the generation of these irregularities, uncertainties still exists in understanding the evolution of the irregularities at various spectral scales and their day-to-day and longitudinal variabilities (e.g. Abdu, 2001). While radar observations have been used to study the temporal evolution of small scale irregularities, it has to be noted that radar signal alone can not always specify whether the small scale irregularities are generated in situ or further to the west from a particular station. Similarly, while the GPS observations of TEC and L-band scintillations provide the distribution of irregularities for various zenith and azimuthal directions, it's drawback is that it does not provide temporal variation of the irregularities at a particular location. Hence, no single instrument can provide the above mentioned information at a time. Several campaigns using multi-instrument observations in a coordinated manner have also been used in the past to derive information for characterizing the ESF irregularities (e.g. Kelley et al., 1986; Valladares et al., 1996; Basu et al., 1996; de Paula et al., 2004).

In this paper, we present for the first time simultaneous observations of ESF over the Indian region using both radar and GPS receivers, which are sensitive to irregularities with different scale sizes (radar is sensitive to $\sim 3 \mathrm{~m}$ and the first Fresnel zone for GPS L1 scintillations is $\sim 370-400 \mathrm{~m}$ ). While simultaneous observations of radar echoes and GPS signals have been made earlier at other equatorial regions (e.g. Kelley et al., 1996; Valladares et al., 2004; Rodrigues et al., 2004), no such observations have been reported for the Indian region. The observations that we present here will not only provide additional information on the generation and evolution of plasma irregularities at two different scales but also on the latitudinal and longitudinal extent of scintillations and TEC at the time of ESF event. The main objective of this paper is to correlate the radar echoes with GPS L-band scintillations and TEC fluctuations and to bring out some of the important features of evolution of ESF irregularities during various types of radar echoes. The GPS observations that we present here were made under GAGAN (GPS Aided GeoAugmented Navigation) project.

\section{Experimental details}

The observations reported here were made simultaneously with the Indian MST radar located at Gadanki $\left(13.5^{\circ} \mathrm{N}\right.$, $79.2^{\circ} \mathrm{E}$, Dip latitude $6.3^{\circ} \mathrm{N}$ ) and GPS on few occasions during the years 2004 and 2005. Indian MST Radar is a monostatic coherent radar which operates at a frequency of $53 \mathrm{MHz}$ (Rao et al., 1995). The MST radar antenna array is aligned along the geomagnetic axis in such a way that it can be used to study the ionospheric plasma irregularities. The radar beam is tilted at $14-16^{\circ}$ to the vertical towards north to make it perpendicular to geomagnetic field lines at different heights of the $\mathrm{F}$ region in order to detect the field aligned 
Table 1. Radar experimental parameters used for spread F observations.

\begin{tabular}{ll}
\hline Parameter & Value \\
\hline Radar frequency & $53 \mathrm{MHz}$ \\
Transmitter peak power & $2.5 \mathrm{MW}$ \\
Antenna beam width & $3^{\circ}$ \\
Antenna & $32 \times 32$ \\
Antenna gain & $36 \mathrm{~dB}$ \\
Beam direction & $14-16^{\circ} \mathrm{N}$ off-zenith \\
Pulse width & $16 / 32 \mu \mathrm{s}$ \\
Coded & Uncoded \\
Inter-pulse period & $5 \mathrm{~ms}$ \\
Number of coherent integration & 1 \\
Number of FFT point & 256 \\
Number of spectral averaging & $4 / 8$ \\
Velocity window & $\pm 283 \mathrm{~m} \mathrm{~s}^{-1}$ \\
Range resolution & $2.4 / 4.8 \mathrm{~km}^{-1}$ \\
Velocity resolution & $2.25 \mathrm{~m} \mathrm{~s}^{-1}$ \\
\hline
\end{tabular}

irregularities. The radar observes back scattered echo only when irregularities of scale size equal to half the probing wavelength are present so that Bragg's condition is satisfied. Hence, this radar is sensitive to approximately $3 \mathrm{~m}$ scale size $(\lambda / 2$, where $\lambda$ is radar wavelength) irregularities present in the ionosphere. The radar observations basically provide signal-to-noise ratio (SNR), Doppler velocity and spectral width as a function of height and time. The main parameters of the radar are given in Table 1.

Around 18 dual frequency GPS receivers have been installed under GAGAN project to study the Equatorial and low latitude ionosphere and also to model the ionosphere in this region for use in aviation over Indian region (Ramarao et al., 2006a). Figure 1 shows the chain of GPS receiver stations installed in the Indian sector under GAGAN project. Also presented is the location of Indian MST radar in the same map. The type of receiver that is being used to collect the TEC and scintillations data here is GSV 4004 A Ionospheric Scintillation Monitor (ISM) (Van Dierendonck et al., 1996; Ramarao et al., 2006b). Each GPS receiver can track up to $11 \mathrm{GPS}$ C/A-code signals at L1 frequency $(1.575 \mathrm{GHz})$. The data collected is used to obtain for every 1-min interval statistical parameters like $S_{4}$ index, which is the standard deviation of normalized intensity of the signal, standard deviation of phase, receiver lock time etc. for each satellite being tracked. The GPS satellites basically transmit radio signals at two frequencies namely L1 $(1.575 \mathrm{GHz})$ and L2 $(1.227 \mathrm{GHz})$. The dispersive nature of the ionosphere causes the two radio signals to propagate at different velocities, producing a time delay for each signal by a certain amount. This time delay, which is normally much smaller than the total transit time, is proportional to the total electron content along the line of sight to the satellite. Using the time delays for the two signals and also the more accurate phase information,

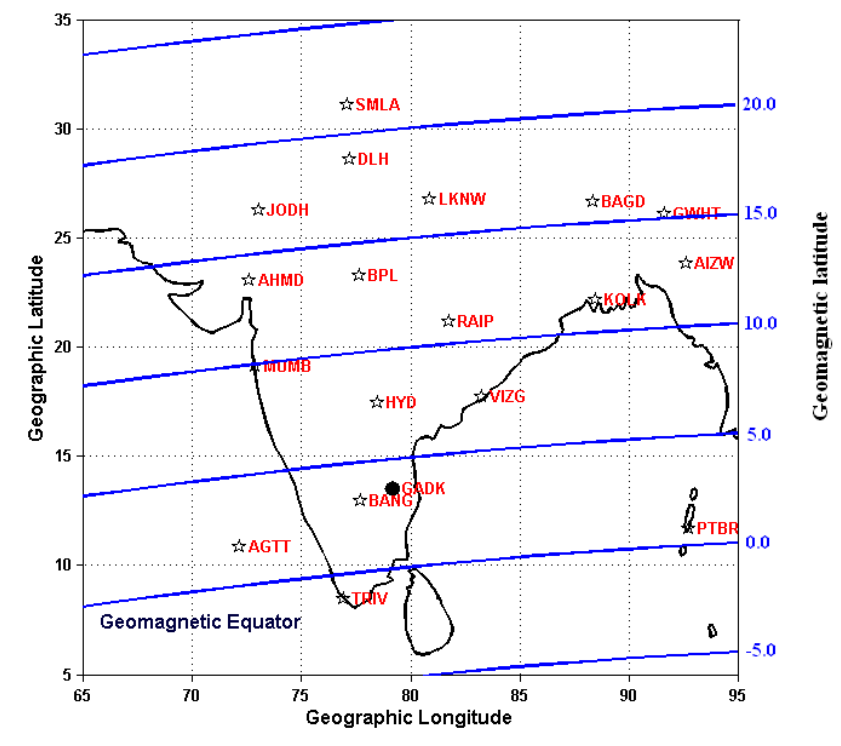

Fig. 1. A chain of GPS receiver stations installed under GAGAN project over Indian region. Also can be seen is the MST radar location as a dark circle in the map.

the slant TEC (STEC) is obtained. Scintillations are produced when the signals travel through a turbulent medium, where changes in the refractive index produce scattering. If the irregularities are confined to a layer of thickness less than $100 \mathrm{~km}$, when the radio waves emerge from the irregularity layer, only a phase perturbation is imposed due to the irregularities. Further propagation of the radio waves to the plane of the receiver produces amplitude fluctuations in addition to phase fluctuations. For weak scintillation, maximum contribution to the amplitude fluctuation comes from irregularities having scale size of the first Fresnel zone, which depends on the signal wavelength and average height of the irregularity layer. For GPS, this scale works out to be $\sim 370-400 \mathrm{~m}$. Hence, GPS L-band scintillations require the presence of a few hundred meters scale size irregularities. The strength of this scintillation is represented by " $S_{4}$ Index" which has been defined above and is used to monitor the strength of amplitude scintillations at L1 frequency. The $S_{4}$ index and STEC data thus recorded are processed for each of the satellite passes with an elevation mask angle greater than $30^{\circ}$, so as to eliminate the effects of multi path and tropospheric scattering. From the STEC, the vertical TEC (VTEC) is calculated using appropriate mapping function, $S_{f}=\cos \chi$, i.e. $\mathrm{VTEC}=\mathrm{STEC} * \cos \chi$ where $\chi=\sin ^{-1}\left[R_{E} \cos \alpha /\left(R_{E}+h\right)\right]$, $\alpha$ is the elevation angle, $R_{E}=$ Earth's radius, $h=400 \mathrm{~km}$. To identify the presence of small scale irregularities in the TEC, a quantity DROTI, which is the standard deviation of the second derivative of STEC, is computed at every $5 \mathrm{~min}$. The fluctuations in TEC as represented by DROTI may be theoretically related to the $S_{4}$-index, which is not possible with the more commonly used ROTI (Bhattacharyya et al., 2000). 


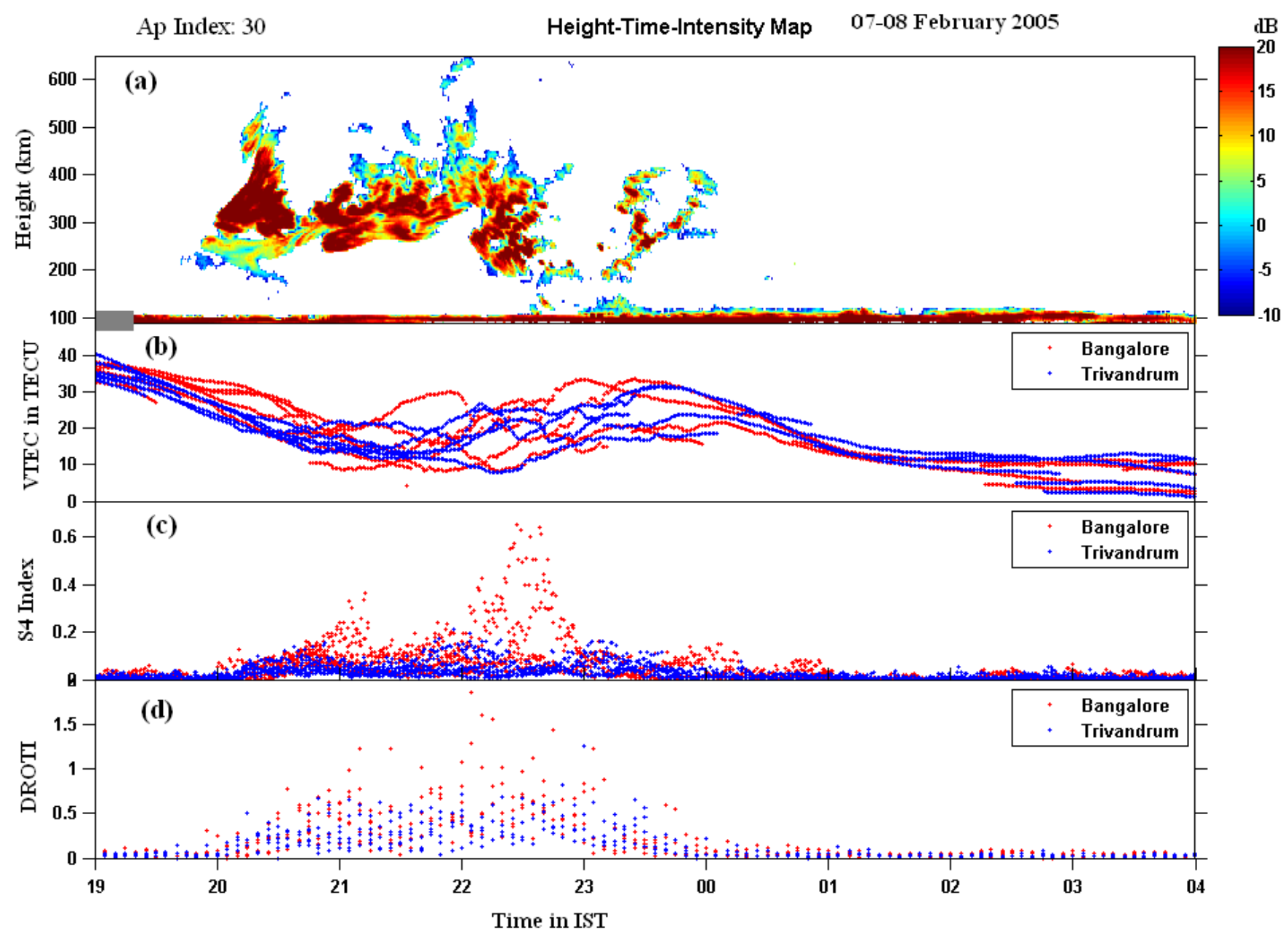

Fig. 2. The height-time-intensity (HTI) map, VTEC, $S_{4}$ index and DROTI as a function of time during 7-8 February 2005, respectively. Note that data gap is represented by gray thick line in the radar map.

\section{Observations}

In order to characterize the equatorial spread $\mathrm{F}$ irregularities, observations are classified broadly into three categories which are presented as (a) plume (bubble) type irregularities, (b) bottom type irregularities and (c) post mid-night irregularities, respectively based on their appearance in the HeightTime-Intensity (HTI) maps. The latitudinal and longitudinal distribution of GPS TEC and L-band scintillations obtained at various stations have been used to investigate the background conditions during various types of ESF events. The azimuth and elevation angles have been used to obtain the latitude and longitudes of the Ionospheric Penetration Point (IPP) for each measurement by assuming the height of the IPP to be $400 \mathrm{~km}$.

\subsection{Case 1: Plume (bubble) type irregularities}

Figure 2a-d shows the height-time-intensity (HTI) map, VTEC, $S_{4}$ index and DROTI as a function of time during
7-8 February 2005, respectively. The $A_{p}$ index on this day is 30 and it is a moderately magnetically active day. Figure $2 \mathrm{a}$ shows that while $\mathrm{E}$ region echoes were present right from 19:00 IST, radar echoes started appearing initially at the height of $250 \mathrm{~km}$ at about 19:45 IST as a weak layer. However, as time progressed the radar echoes started appearing at various heights and these echoes reached as high as $600 \mathrm{~km}$ in the form of plume structures. The HTI map suggests that these echoes are very intense and exhibits complex electrodynamics. The signal strength of the radar echoes is found to be more then $20 \mathrm{~dB}$. Though several structures appeared in the HTI map, broadly three plume structures can be noticed. The first and second plume appear at 20:30 and 22:15 IST, last one is found to appear around 23:30 IST. Though this day is somewhat magnetically active $\left(A_{p}\right.$ index: 30$)$, the irregularities did not extend to early morning hours. Figure $2 b$ shows VTEC as a function of time as observed over equatorial locations of Trivandrum (TRV), and Bangalore (BANG). Here it may be noted that we have taken the data 

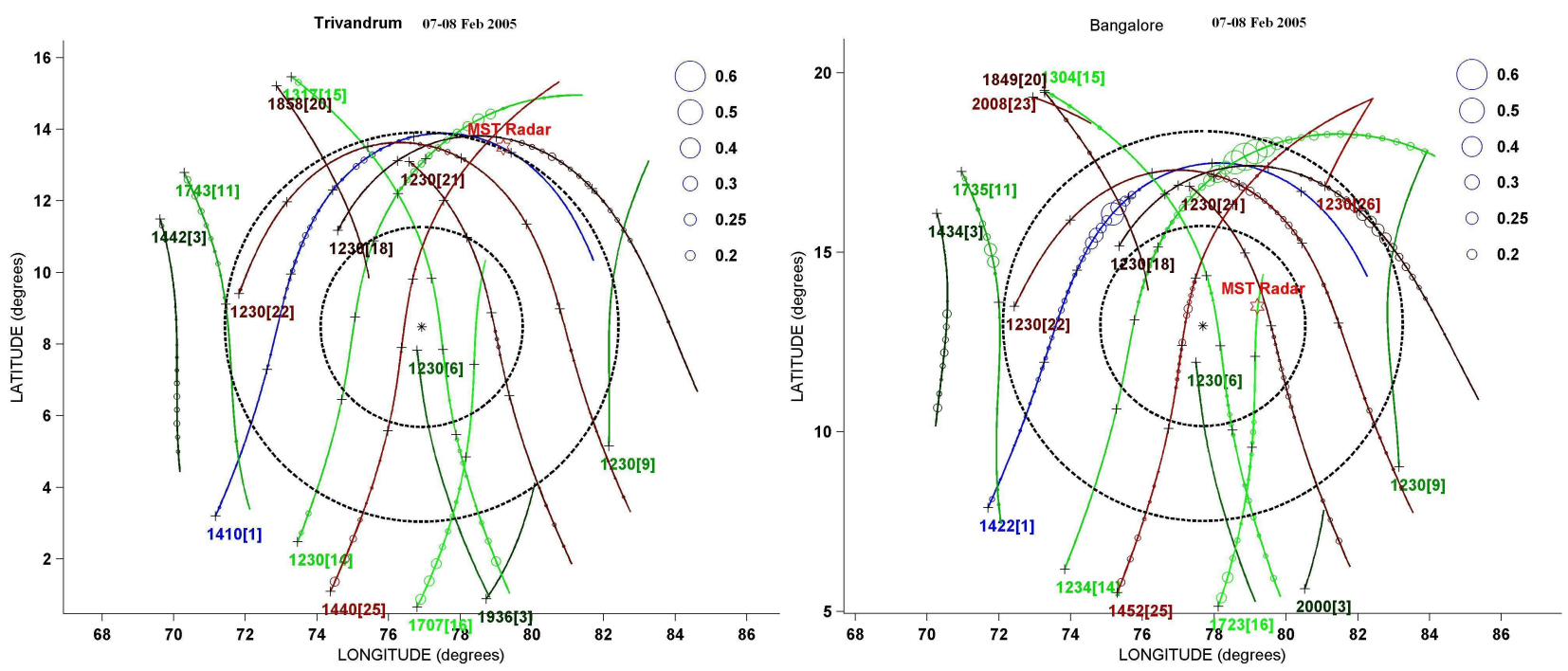

Fig. 3. The polar plots corresponding to the Trivandrum and Bangalore stations on 7-8 February 2005, respectively. Here the inner circle indicate elevation $>50 \mathrm{deg}$ and outer circle represent elevation $>30 \mathrm{deg}$.

07-08 February 2005
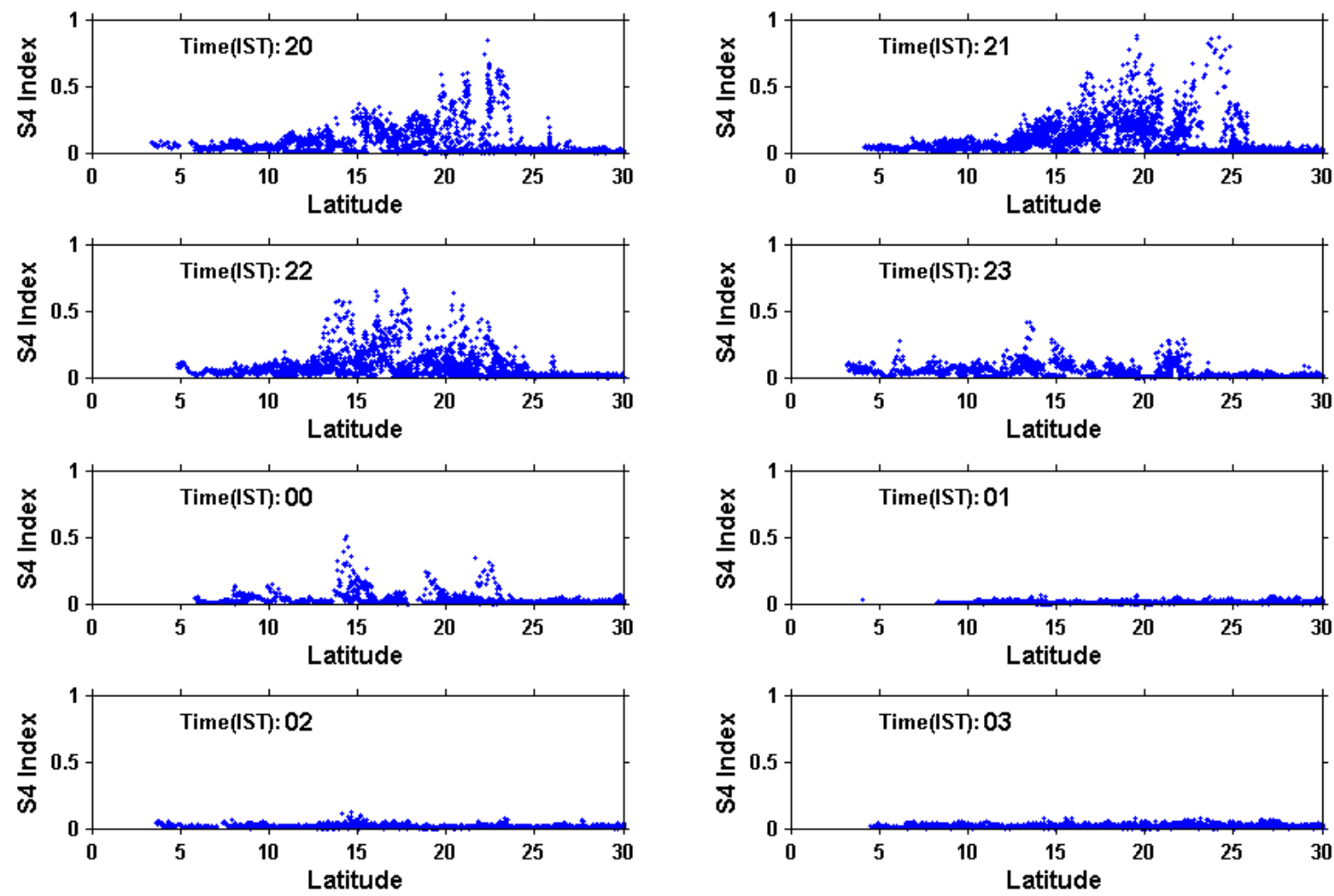

Fig. 4. The latitudinal distribution of $S_{4}$ index at different timings on 7-8 February 2005.

corresponding to the elevation angle $>30^{\circ}$. The VTEC varies from as low as 3 TECU $\left(1 \mathrm{TECU}=1 \times 10^{16}\right.$ electrons $\left./ \mathrm{m}^{2}\right)$ to as high as $40 \mathrm{TECU}$ and slowly decreases as time progresses. Observations suggest that during the time of ESF event in the radar map, the VTEC also shows depletions or density fluctuations. This can be seen in the parameter DROTI in the Fig. 2d. Figure 2c represents the strength of amplitude scintillations on L1 frequency for the time interval 


\section{7-08 February 2005}
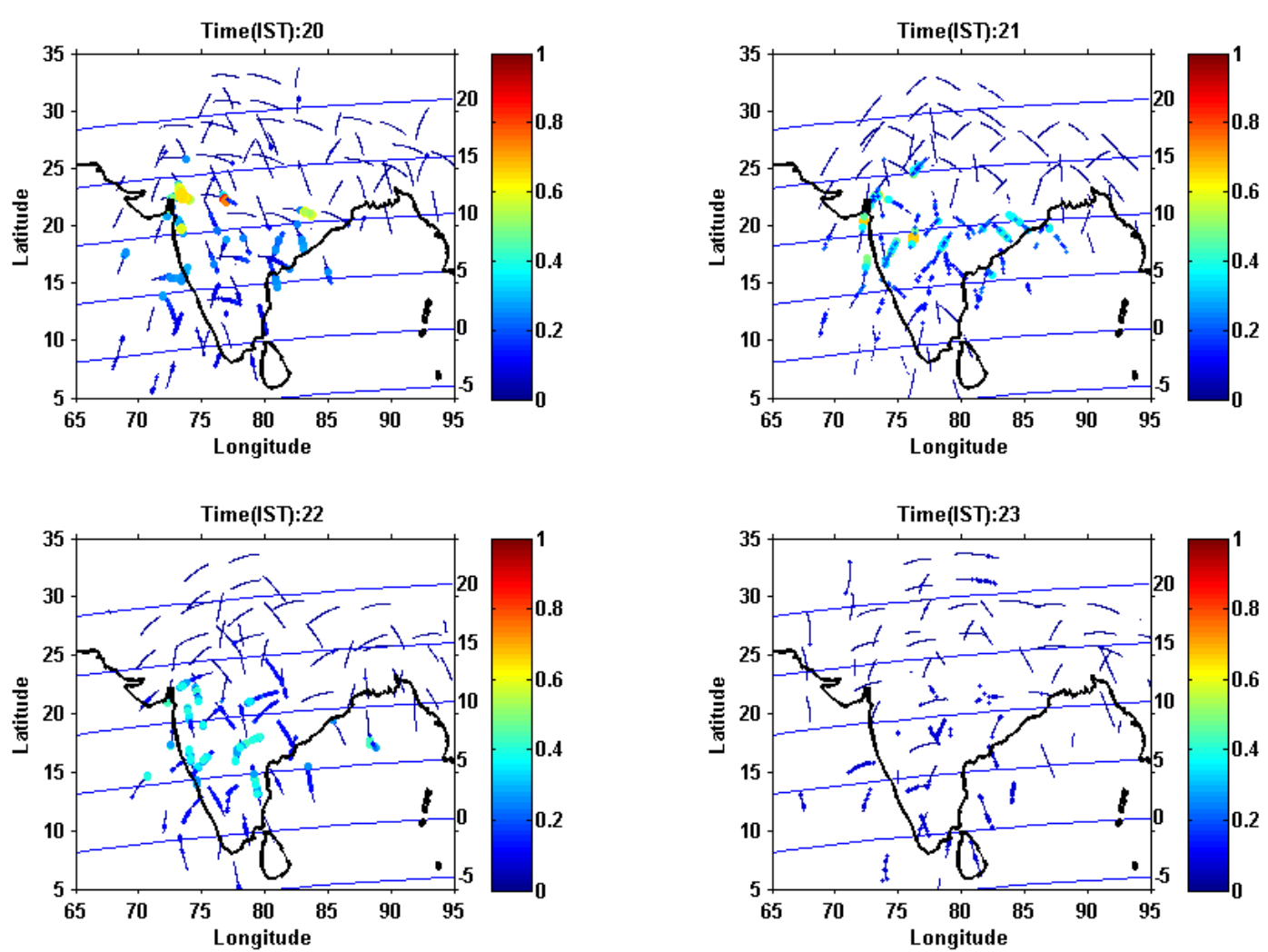

Fig. 5. The scatter plot of $S_{4}$ index as a function of latitude and longitude superposed onto the Indian map for (a) 20:00-21:00 IST, (b) 21:0022:00 IST, (c) 22:00-23:00 IST and (d) 23:00-34:00 IST, respectively, on 7-8 February 2005. Here the y-axis on the right side represents the geomagnetic latitude.

19:00-04:00 IST. It can be seen that while the $S_{4}$ index goes as high as 0.7 over BANG station, TRV station shows $S_{4}$ index only as high as 0.25 which is much less than that at BANG station. To study the scintillations with respect to location of the IPP elevation and azimuthal directions, polar plots corresponding to the TRV and BANG stations are plotted in Fig. 3a-b. Here, the station location is indicated by star $(*)$. The inner circle represents the elevation angle of $50^{\circ}$, while the outer circle represents elevation angle of $30^{\circ}$. Here initial time of each PRN is displayed in UT and every subsequent hour is represented by "+" symbol only for the tracks which crossed the $S_{4}$ index threshold. The threshold used for $S_{4}$ index is as follows: the running 5 min of mean $S_{4}$ index should exceed a value of 0.05 for more than $5 \mathrm{~min}$. The polar plot shown in Fig. 3a suggests that initially scintillations start appearing at 21:00 IST in the northwest side of the TRV station and later on the scintillations are extended to further northern side. At almost the same time, BANG station started recording the scintillations on the west and north sides. The GPS satellite for which the IPP of the satellite to BANG signal path moved closest to radar site is found to be PRN 21 and 16 as can be noted from the figure. How- ever the time when the IPP was closest to the radar site was close to 14:00 UT which corresponds to 19:30 IST just before the bubble had started to grow. Figure $4 \mathrm{a}-\mathrm{h}$ shows the latitudinal distribution of $S_{4}$ index on L1 at different timings for all the satellites which fall above elevation angle of 30 deg. for the corresponding night. The latitudinal distribution of $S_{4}$ index is found to maximize around $24^{\circ} \mathrm{N}$. Also the time period at which maximum scintillations occurred is found to be $\sim 20: 00-22: 00$ IST. Closer observations suggest that weak scintillations have been observed near to radar site after 14:30 UT (20:00 IST) which coincides with the radar echoes.

Figure 5a-d represents the scatter plot of $S_{4}$ index on L1 as a function of latitude and longitude superposed on the Indian map for (a) 20:00-21:00 IST, (b) 21:00-22:00 IST, (c) 22:00-23:00 IST and (d) 23:00-24:00 IST, respectively, on 7-8 February 2005. The color and size of the circle indicates the strength of the $S_{4}$ index at that particular time. The observations reveal that while the $S_{4}$ index at the low latitudes is found to be about 0.4 , it reaches 0.7 at about magnetic latitude of $15^{\circ}$ during 20:00-22:00 IST. L-band scintillations have been observed over the entire band of magnetic latitude 


\section{7-08 February 2005}
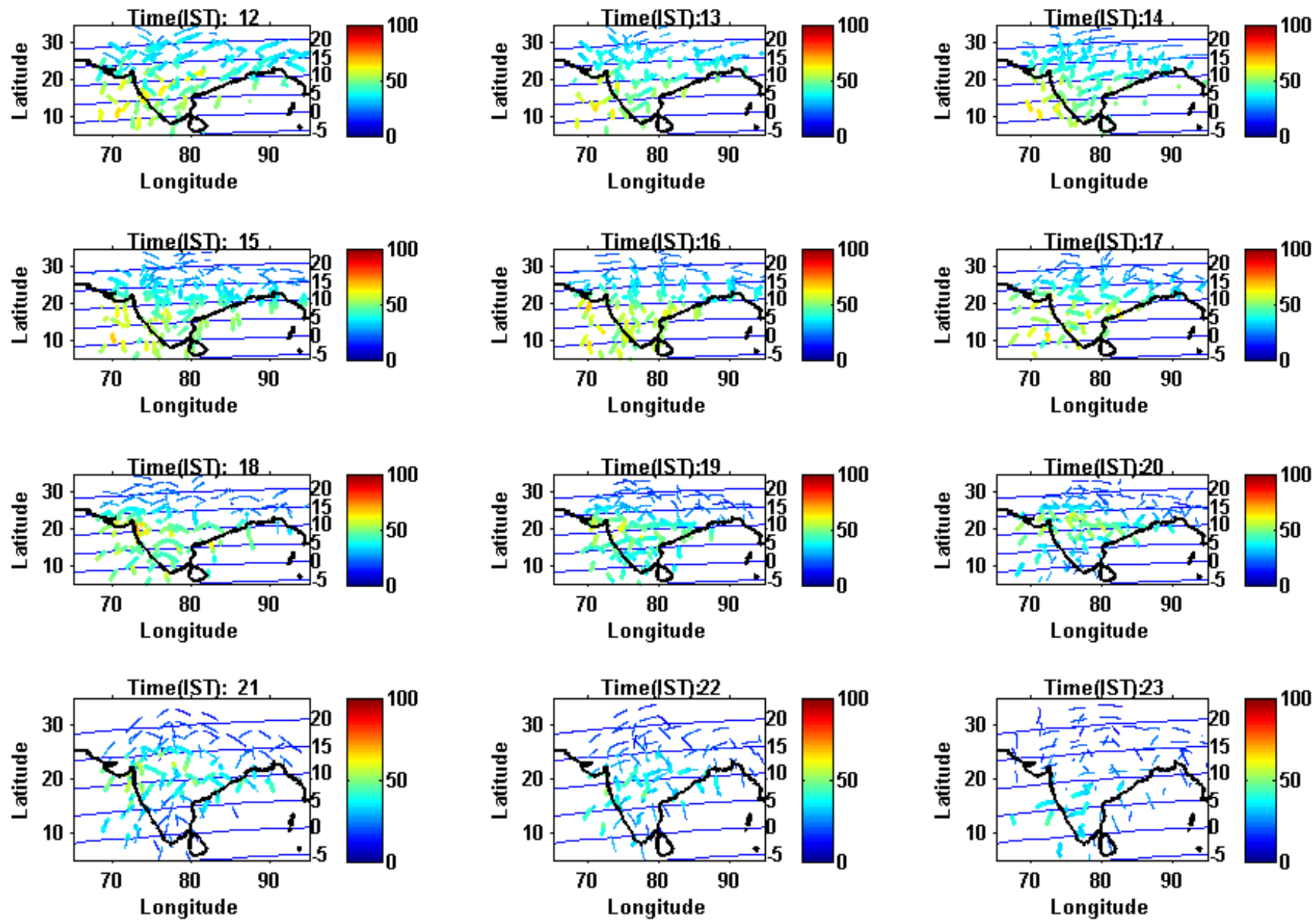

Fig. 6. The VTEC plotted on 7-8 February 2005 starting from 12:00 IST to 23:00 IST with an interval of one hour. Here the y-axis on the right side represents the geomagnetic latitude.

from $5^{\circ}$ to $15^{\circ}$ degrees. The maximum scintillations have been found to occur at about 20:00-22:00 IST. Figure 6a-1 represents the VTEC plotted in a manner similar to $S_{4}$ Index for the same day starting from 12:00 IST to 23:00 IST for every one hour. The size and color of the circle in the each plot is indicative of the strength of the TEC at that particular time. Here it may be noted that a weak equatorial ionization anomaly is formed at 19:00 IST and it extends to up to $15^{\circ}$ magnetic latitude between 20:00 and 21:00 IST.

\subsection{Case 2: Bottom type irregularities}

Figure $7 \mathrm{a}-\mathrm{d}$ shows the height-time-intensity (HTI) map, VTEC, $S_{4}$ index and DROTI respectively as a function of time during 21-22 March 2004, similar to that of Fig. 2ad. The $A_{p}$ index on this day is 11 and it is a magnetically quiet day. Figure 7 a reveals that the $F$ region plasma irregularities are mostly observed at lower heights $(<300 \mathrm{~km})$ at about 20:30 IST in the initial period and it does not extend to higher altitudes. These irregularities are observed in the form of very thin layer having width of $50 \mathrm{~km}$. Also, the strength of the small scale irregularities is found to be very weak at most of the times. But as time progresses, the small scale irregularities, some times, found to extend to heights as high as $400 \mathrm{~km}$. The E region echoes are also seen in this HTI map but they are very weak and intermittent. Figure $7 \mathrm{~b}$ shows the VTEC as a function of time for the corresponding period at TRV and Port Blair (PTBR). It may be noted that Portblair $\left(11.67^{\circ} \mathrm{N}, 92.72^{\circ} \mathrm{E}\right)$ is located about $16 \mathrm{de}-$ grees east of Trivandrum. Unfortunately, on this day, data is not available from BANG station. The $S_{4}$ index at TRV is shown in Fig. 7c. At TRV, the strength of the $S_{4}$ index for L1 is lower when comparing to the earlier. Figure $8 \mathrm{a}-\mathrm{b}$ shows the polar plots corresponding to the stations (a) TRV and (b) PTBR, which are quite similar to the Fig. 3a-b. The polar diagram shown over TRV indicates that weak $S_{4}$ index is seen in the northwest side of the radar site around 17:30 UT 


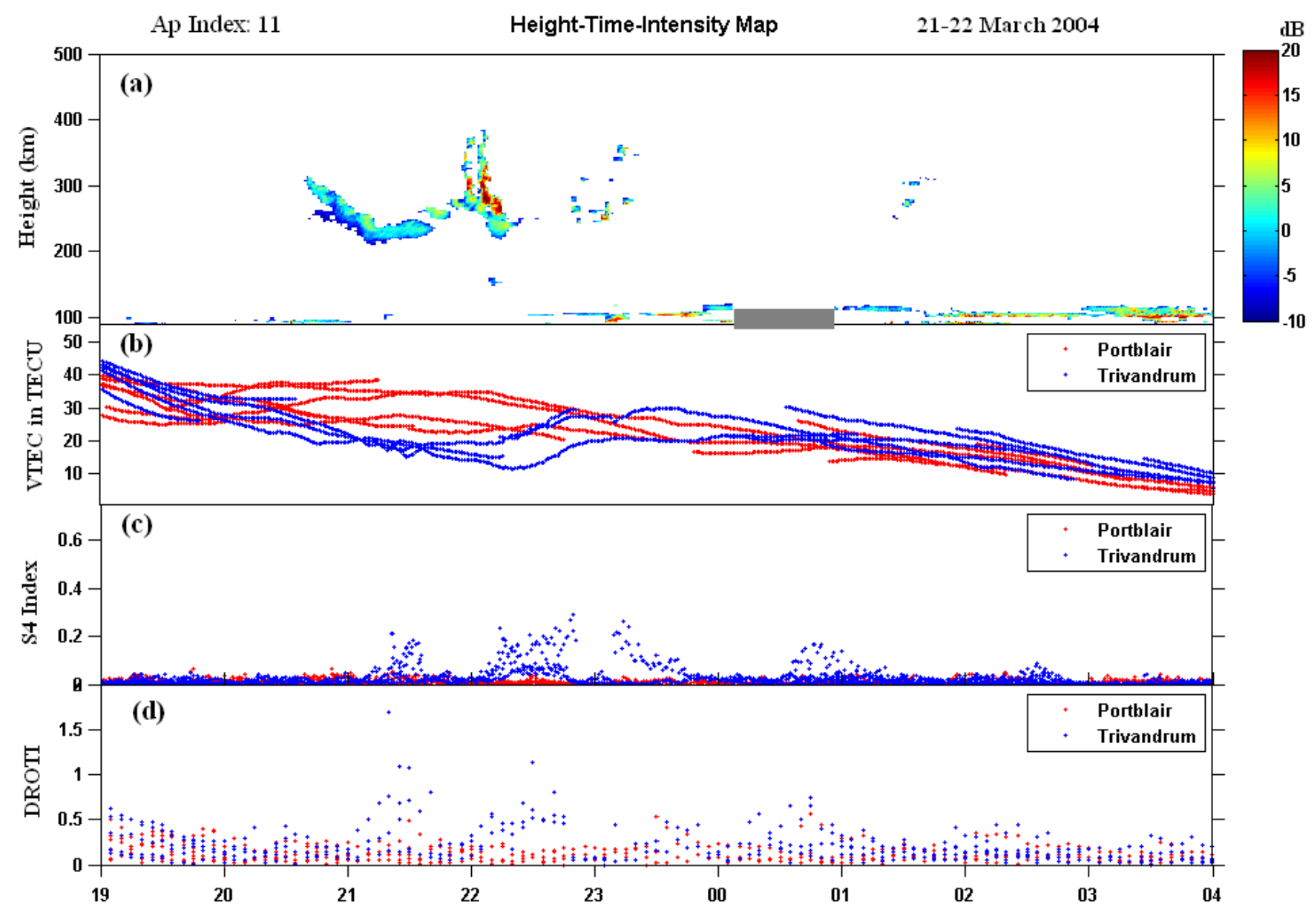

Time in IST

Fig. 7. The height-time-intensity (HTI) map, VTEC, $S_{4}$ index and DROTI as a function of time during 21-22 March 2004, respectively. Note that data gap is represented by gray thick line in the radar map.

(23:00 IST). The polar diagram over PTBR shows no scintillation. Further, the analysis of $S_{4}$ index indicates that on this night, scintillations have been observed only at Trivandrum and Mumbai (MUMB) stations which are in western side of India. However, scintillations have not been observed at Kolkatta (KOLK) and Portblair stations which are in the eastern side of the India. Though this analysis is performed, we have not shown here due to limited space. Hence, we assume that the irregularities are highly restricted in longitude and occurred only in narrow longitude band. Figure $9 \mathrm{a}-\mathrm{h}$ shows the latitudinal variation of $S_{4}$ index at different timings for the same night. From the figure, it is clear that $S_{4}$ index is small at higher magnetic latitudes.

Figure 10a-1 represents the VTEC plotted in a manner similar to the $S_{4}$ index for the same day starting from 12:00 IST to 23:00 IST for every one hour. On this day the TEC is much larger throughout the day compared to that on 7 February 2005. Although a strong EIA is seen during postsunset hours, it is possible that on this day, various other fac- tors such as F region height, PRE and thermospheric neutral winds could have inhibited the EPB generation. It is also possible that on this day, the electron densities are high in the E region at the feet of geomagnetic field-lines connecting to the bottomside of the F-region. This would prevent the development of EPBs and the R-T instability would evolve into $\mathrm{km}$ scale bottomtype irregularities (Bhattacharyya, 2004).

\subsection{Case 3: Post mid-night irregularities}

Figure $11 \mathrm{a}-\mathrm{d}$ shows the height-time-intensity (HTI) map, VTEC, $S_{4}$ index and DROTI respectively as a function of time during 27-28 May 2004. The $A_{p}$ index on this day is 04 and it is a magnetically quiet day. Figure 11a shows that the $\mathrm{F}$ region plasma irregularities of $\sim 3 \mathrm{~m}$ scale size started appearing above Gadanki at about mid-night and extended till next day morning 04:00 IST. Here, the appearance of the irregularities is found to be of plume type and the irregularities have been observed at heights as high as $500 \mathrm{~km}$. 

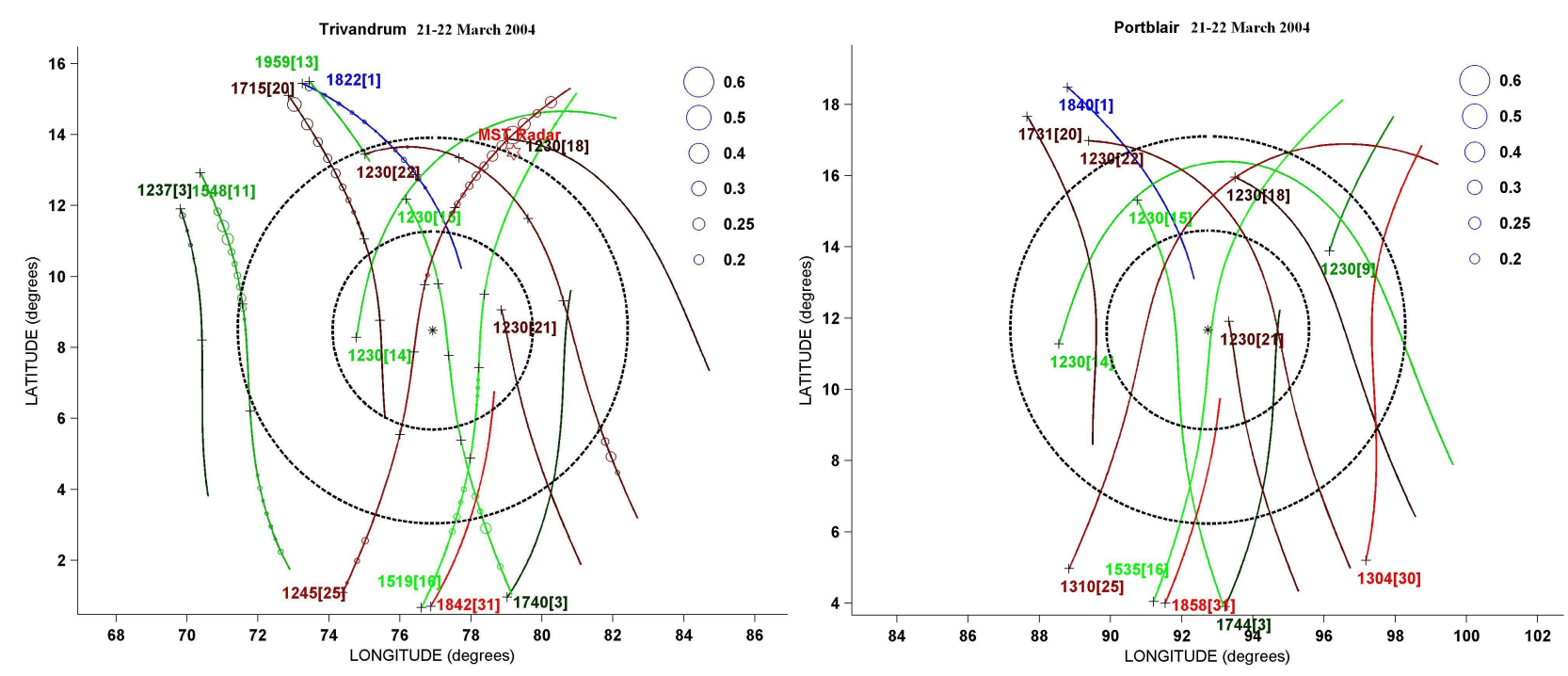

Fig. 8. The polar plots corresponding to the stations (a) Trivandrum and (b) Port Blair on 21-22 March 2004, respectively. Here the inner circle indicate elevation $>50 \mathrm{deg}$ and outer circle represent elevation $>30 \mathrm{deg}$.

The observations suggest that the plumes have multi echoing structures and are separated in time by about half an hour. Also the strength of the small scale irregularities is found to be very high at most of the times. On this night, the upper E region echoes display QP echoes in the pre-midnight. The QP echoes having positive striation with vertical wavelengths of $20-25 \mathrm{~km}$ can be seen in the HTI map. When F region echoes started appearing in the radar map, we see disappearance/weakening of $\mathrm{E}$ region echoes. In Fig. 11b, the density fluctuations present in VTEC, which are revealed in DROTI, correspond to scale sizes of $\sim 3 \mathrm{~km}$ if we consider the irregularities to drift across the signal path with a velocity of $\sim 50 \mathrm{~m} / \mathrm{s}$. In Fig. 11c, it can be noted that very weak Lband scintillations $\left(S_{4}<0.2\right)$ have been recorded at both TRV and BANG stations. However, DROTI, shown in Fig. 11d, suggests that there are TEC fluctuations recorded at both station. This indicates that TEC fluctuation do exist without Lband scintillations also. Figure 12a-h shows the latitudinal variation of $S_{4}$ index on L1 at different timings for the corresponding night. From the figure, it is clear that the $S_{4}$ index is negligibly small. The L-band $S_{4}$ index does not show any significant scintillations on the L1 frequency on this night. In Fig. 13a-l it is seen that on this day the equatorial ionization anomaly is not formed at all.

\section{Results and discussion}

The observations presented in Sect. 3.1 reveal that significant GPS L band scintillations, depletions in TEC and DROTI observed at locations close to the dip equator are associated with the strong plume type radar echoes extending to high altitudes during pre-midnight period. L band scintillations in this case 1 are considerably stronger at low latitude stations relative to that of other two cases presented. The GPS observations also show intense $\mathrm{L}$ band scintillations at wide range of latitudes for this situation. The observations also show that for plume type radar echoes in the pre-midnight period, the observed scintillations extend to higher latitudes. This can be explained by the field line mapping of the irregularity structures to higher latitudes during ESF events showing plume type structures that extend to higher altitudes. In contrast, when low altitude echoes and weak echoes are seen during early phase at radar site, L band scintillations are found to be weaker/absent at low latitude stations. Absence of L-band scintillations at higher latitudes during bottom type ESF events can also be understood through field line mapping. Valladares et al. (2004) have presented GPS TEC and scintillation measurements using a network of GPS receivers at Peru. They have found that intense GPS scintillations coincide with the TEC depletions and radar plumes. Our results support their observations that strongest L-band scintillations occur at EIA crest locations in association with radar plumes whereas bottomtype irregularities are associated with weak L-band scintillations. Observations using GPS and radar at an equatorial station in Brazil are reported by Rodrigues et al. (2004). They have also shown that there is a strong correlation between plume type irregularities and $S_{4}$ index at L1 frequency. Further, their observations reveal that small-scale irregularities seen in the radar are short lived as compared to the L-band scintillations, which are associated with irregularities of scale size $\sim 370-400 \mathrm{~m}$ as well as ionosonde observations of spread $\mathrm{F}$ (scale size of tens of meters). This they have attributed to the earlier decay of smaller scale size irregularities due to diffusion. However, due to 


\section{1-22 March 2004}
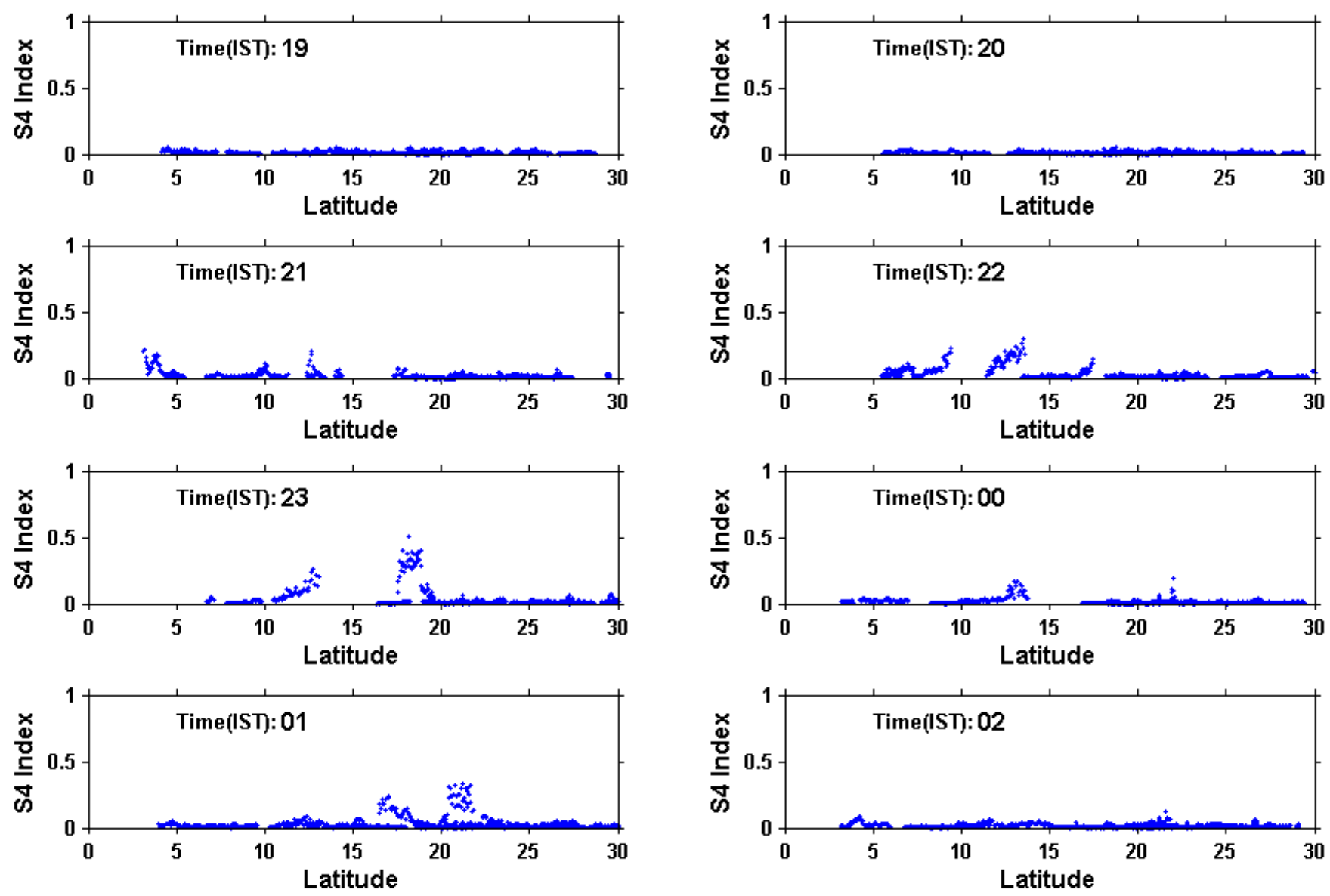

Fig. 9. The latitudinal variation of $S_{4}$ index at different timings on 21-22 March 2004.

lack of GPS observations at other locations in their observations, they were not able to study the latitudinal distribution of $S_{4}$ index. The analysis that we have presented here using GAGAN data overcomes this problem. Here we were able to analyze the latitudinal, longitudinal and temporal distribution of $S_{4}$ index over Indian region. However, the observations presented here as a few case studies are for low solar activity period (2004-2005), and hence it reveals the temporal and spatial variation of GPS scintillations and TEC under low solar activity background conditions. Our observations suggest that $S_{4}$ index maximizes around $20^{\circ}-25^{\circ} \mathrm{N}$ geographic latitude during pre-midnight plume type irregularities. Further, our observations also suggest that $\mathrm{L}$ band scintillations are found to be strong at the equatorward edge of the EIA where the Rayleigh-Taylor instability may give rise to a few hundred meter scale size irregularities. This has also been observed by Ramarao et al. (2006a) and Muella et al. (2008). 3-D simulation of RT instability also shown that sharp density gradients do exists at equatorial anomaly latitudes (Keskiken et al., 2003).
While most of the features seen in case- 1 and case- 2 are similar to those of the earlier observations reported elsewhere and also consistent with current theory, the observations that we have presented in case- 3 are different from earlier findings since we do not see any strong L-band scintillations even though strong radar echoes are seen at higher altitudes. The observations further suggest that there is no EIA formation on this day. To understand these observations, we invoke the basic plasma instability processes responsible for generating the irregularities of scale sizes that give rise to radar echoes and GPS scintillations respectively. It is generally observed that after plasma irregularities are generated in the post-sunset hours during magnetically quiet days, they drift to the east with the ambient plasma after about 22:00 LT. Before 22:00 LT, due to the presence of the perturbation electric field associated with the R-T instability, the drift velocity is found to fluctuate randomly whereas after 22:00 LT, when these perturbation electric fields have decayed, the bubbles just drift with the background plasma without any evolution and are called as "dead bubbles" or "fossil structures" (Bhattacharyya et al., 2001). 


\section{1-22 March 2004}
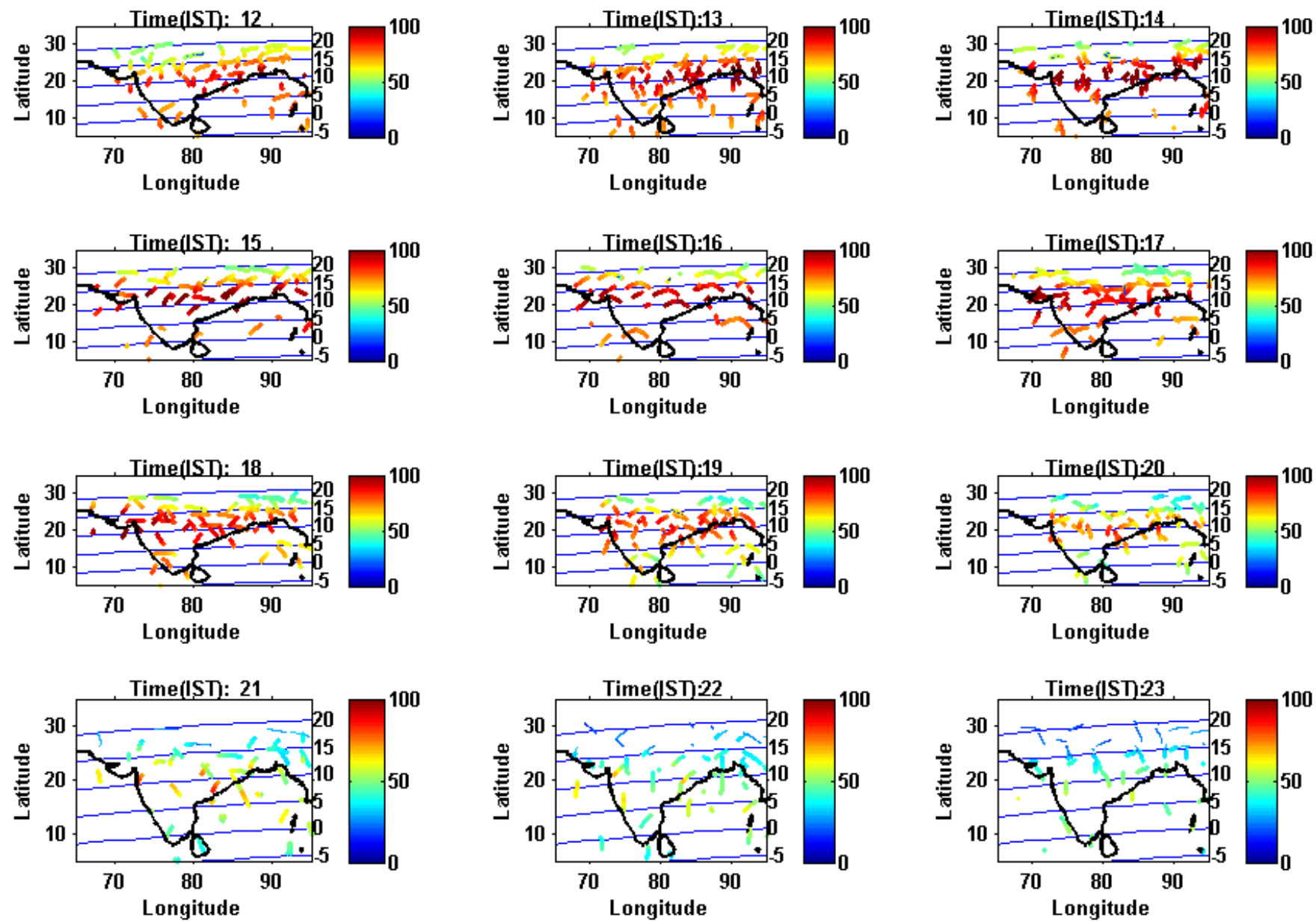

Fig. 10. The VTEC plotted on 21-22 March 2004 starting from 12:00 IST to 23:00 IST for every one hour. Here the y-axis on the right side represents the geomagnetic latitude.

In order to identify whether these irregularities are freshly generated or drifted in from the west, we have plotted the maximum cross-correlation of amplitude scintillations recorded by VHF $(251.45 \mathrm{MHz})$ spaced receivers located at Tirunelveli $\left(8.7^{\circ} \mathrm{N}, 77.8^{\circ} \mathrm{E}\right.$, Dip: $\left.0.4^{\circ} \mathrm{N}\right)$, an equatorial station in India and ionosonde virtual height of the F layer obtained at Trivandrum $\left(8.48^{\circ} \mathrm{N}, 76.95^{\circ} \mathrm{E}\right.$, Dip: $\left.0.5^{\circ} \mathrm{N}\right)$, also an equatorial station along with average spectral width of the radar echoes obtained from Gadanki as a function of time for all three cases. Same is shown in Fig. 14a-c which contain five panels each representing VHF $S_{4}$ index, spectral index $\mathrm{m}$ derived from the slope of the power-law type of spectrum of weak amplitude scintillations, maximum crosscorrelation of spaced receiver scintillation records (Ci), $h^{\prime} F$ from ionosonde observations and average spectral width derived from radar observations respectively on 7-8 February 2005, 21-22 March 2004 and 27-28 May 2004. We could record VHF scintillations on only single receiver at
Tirunelveli instead of spaced receivers on 27-28 May 2004 and hence only spectral index is plotted for 27-28 May 2004. The spectral index is calculated only during weak scintillations where $S_{4}$ index lies between 0.15 and 0.5 , so that the spectral index could be associated with the irregularity power spectrum in accordance with weak scintillation theory. Based on spectral index, we can also identify whether the observed weak scintillations are due to freshly generated irregularities or they are produced by bubbles drifting in from the west. While low spectral index $(\leq 3)$ indicates significant presence of small scale (few hundred meters) irregularities, higher values of spectral index are indicative of decay of these smaller scale size irregularities. Figure14a suggests that during plume type irregularities, the crosscorrelation index $(\mathrm{Ci})$ also falls below 0.5 , while the spectral slopes are found to have values as low as 3 in the early phase of scintillations. However, as time progresses, there is increase in the spectral index (m) as well as $\mathrm{Ci}$ index. The 


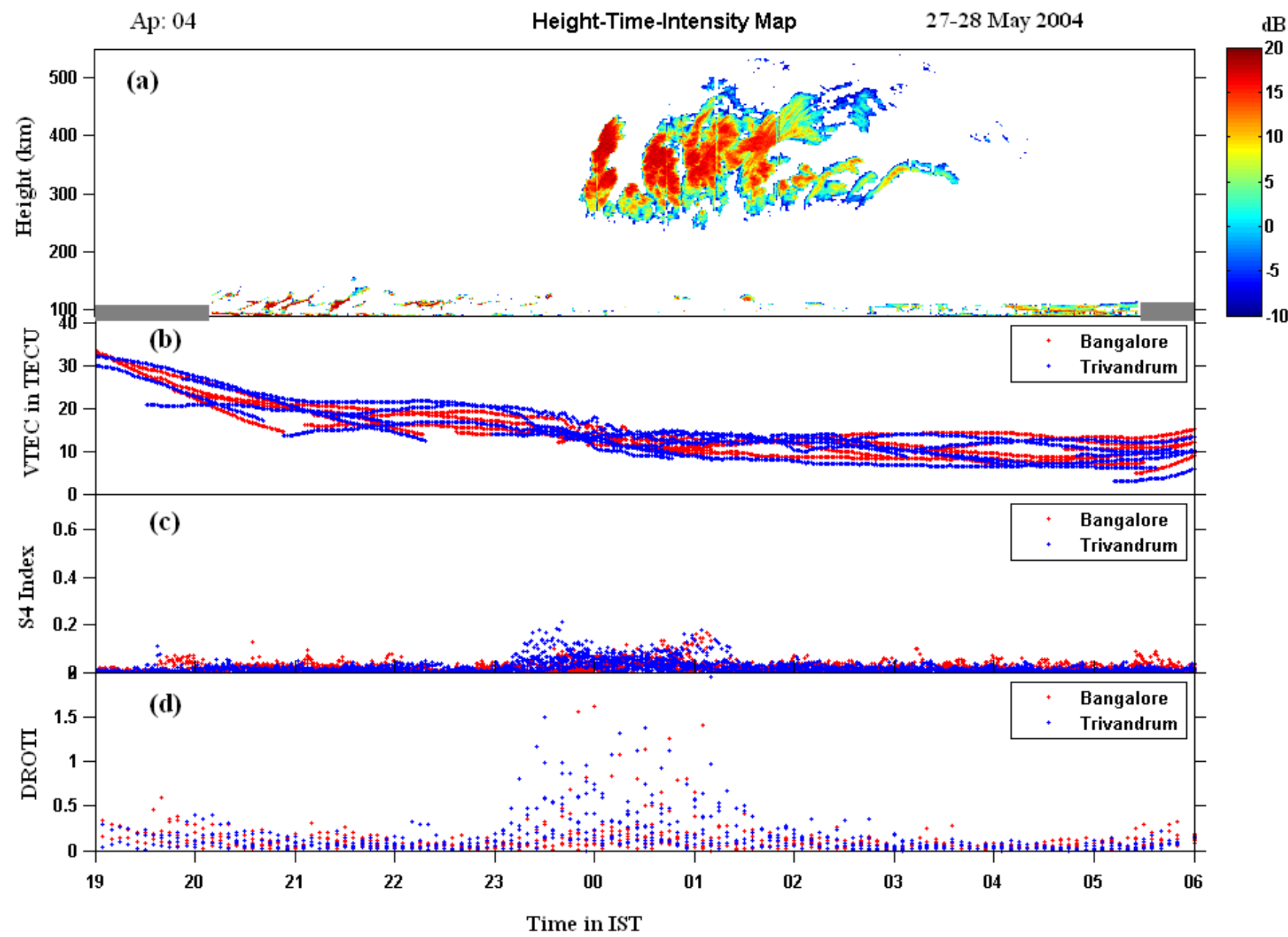

Fig. 11. The height-time-intensity (HTI) map, VTEC, $S_{4}$ index and DROTI as a function of time during 27-28 May 2004, respectively. Note that data gap is represented by gray thick line in the radar map.

height averaged spectral width determined from radar observations in case- 1 in the pre-midnight period is found to have 2 peaks as high as $200 \mathrm{~m} / \mathrm{s}$, while at later times a value of about $100 \mathrm{~m} / \mathrm{s}$ prevails. Ionosonde observation of $\mathrm{F}$ region height over Trivandrum indicates that the $\mathrm{F}$ layer height had increased to $400 \mathrm{~km}$ due to PRE in the post-sunset hours. Figure $14 \mathrm{~b}$ suggests that during bottmtype irregularities, the cross-correlation index is found to be almost 1 except for some time during post-midnight at which time $\mathrm{Ci}$ index is found to be 0.7 . The spectral index is about $4-5$. The height of the F layer is found to increase in the early phase to as high as $375 \mathrm{~km}$. The average spectral width of the radar is found to be as low as $75 \mathrm{~m} / \mathrm{s}$. Figure $14 \mathrm{c}$ suggests that during post-midnight, the spectral index is found to be constant with value of about 5 . The $\mathrm{F}$ layer on this night did not go to very high altitudes during pre-midnight and post-midnight, remaining less than $300 \mathrm{~km}$ throughout the night. The spectral width of the radar is found to be $150 \mathrm{~m} / \mathrm{s}$ and is less than the spectral width observed in the pre-midnight (case-1).
Bhattacharyya et al. (2001) have analyzed VHF scintillation data recorded using spaced receivers and devised a technique to identify whether the irregularities are freshly generated or they are fossil bubbles that have just drifted in from west. They have reported that in the initial growth phase of the plasma bubbles, the maximum cross correlation $(\mathrm{Ci})$ of the spaced receivers' scintillations is found to be low $(<0.5)$ and the zonal drift of the plasma bubbles is found to be highly variable. Based on scintillation observations alone they suggested that the cross correlation index $(\mathrm{Ci})$ of the spaced receivers' scintillations may be used to study the dynamics of the equatorial plasma bubbles. Tiwari et al. (2006) have presented the HF radar observations at TRV made simultaneously with spaced VHF receiver scintillations at Tirunelveli. They have shown that when plume type irregularities have been observed in the radar maps during the growth period, the cross correlation index (Ci) of the spaced receiver signals is low. The spectral width observed by the radar during this time is found to be enhanced and is anti-correlated with that 


\section{7-28 May 2004}
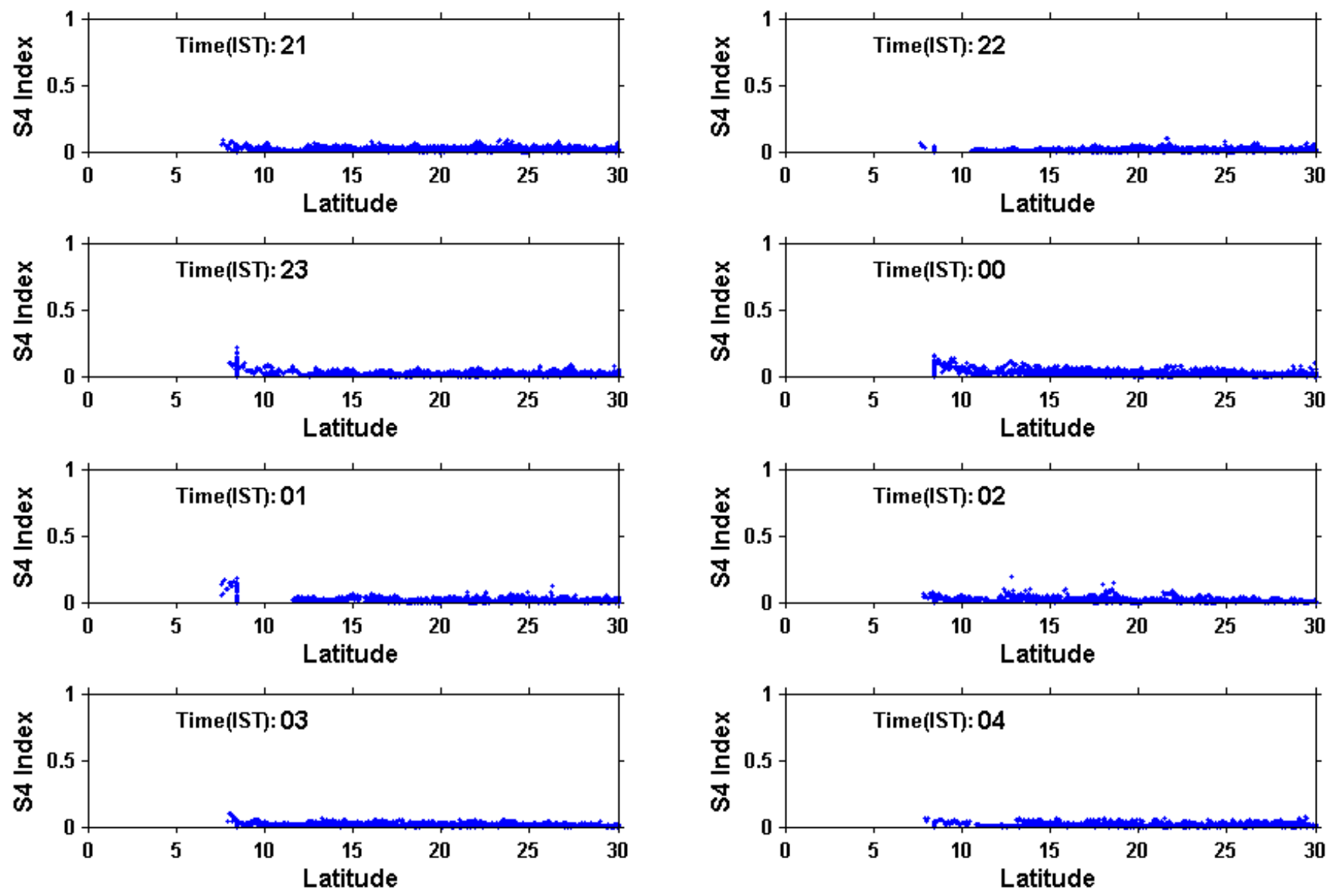

Fig. 12. The latitudinal variation of $S_{4}$ index at different timings on 27-28 May 2004.

of the cross correlation index $(\mathrm{Ci})$. They have attributed this to the increased turbulence in the growth phase of the irregularities. Another study by Patra et al. (2005), who studied the spectral width of two radars using HF and VHF at equatorial stations, also reported that in the initial phase of the plasma bubbles the spectral width is found to be very high $(300 \mathrm{~m} / \mathrm{s})$. The observations of fall in $\mathrm{Ci}$ index below 0.5 and high spectral width during early phase of plume observations by radar, presented by Tiwari et al. (2006) and our observations are in agreement. In contrast to this, when bottomtype irregularities are seen in the radar map, the cross correlation index $(\mathrm{Ci})$ does not decrease. The spectral width observed in the radar during the same time is found to be low. Tiwari et al. (2006) have attributed this to the large scale sinusoidal perturbations on the bottomside of the equatorial $\mathrm{F}$ region. Our observations presented here indicate that the bottomtype irregularities do not contain small scale irregularities of a few hundred meter scale size and also that spectral width observed during bottomtype irregularities is quite low, which is in agreement with the observations of Tiwari et al. (2006). Niranjan et al. (2003) have studied the post mid-night spread
F over Waltair, India, using ionosonde observations. They have suggested that most of the time, post midnight irregularities are found in the summer months and out of them $80 \%$ of the cases were associated with rise of $\mathrm{F}$ layer height to higher altitudes. They further suggested that (a) if spread $F$ occurs following rise in $F$ layer height, occurrence of fresh generation of irregularities is more; and (b) if spread F occurs without rise in F layer height, it could be related to the fossil structures that could have drifted in from west. It is interesting to note that our observation of post midnight also related to summer month. The observations presented here for the case-3 show that (a) F layer height did not rise to higher altitudes during the time of radar echoes, (b) the irregularity power law spectrum derived from weak VHF scintillations has high spectral index, (c) radar echoes have low spectral width and (d) PRE is absent in the pre-midnight hours. So, with these findings, we are in a position to state that these irregularities are not freshly generated over the observation region but they were generated some where to the west of Tirunelveli and Gadanki and drifted to the east as a "dead bubble" or "fossil bubble". 


\section{7-28 May 2004}
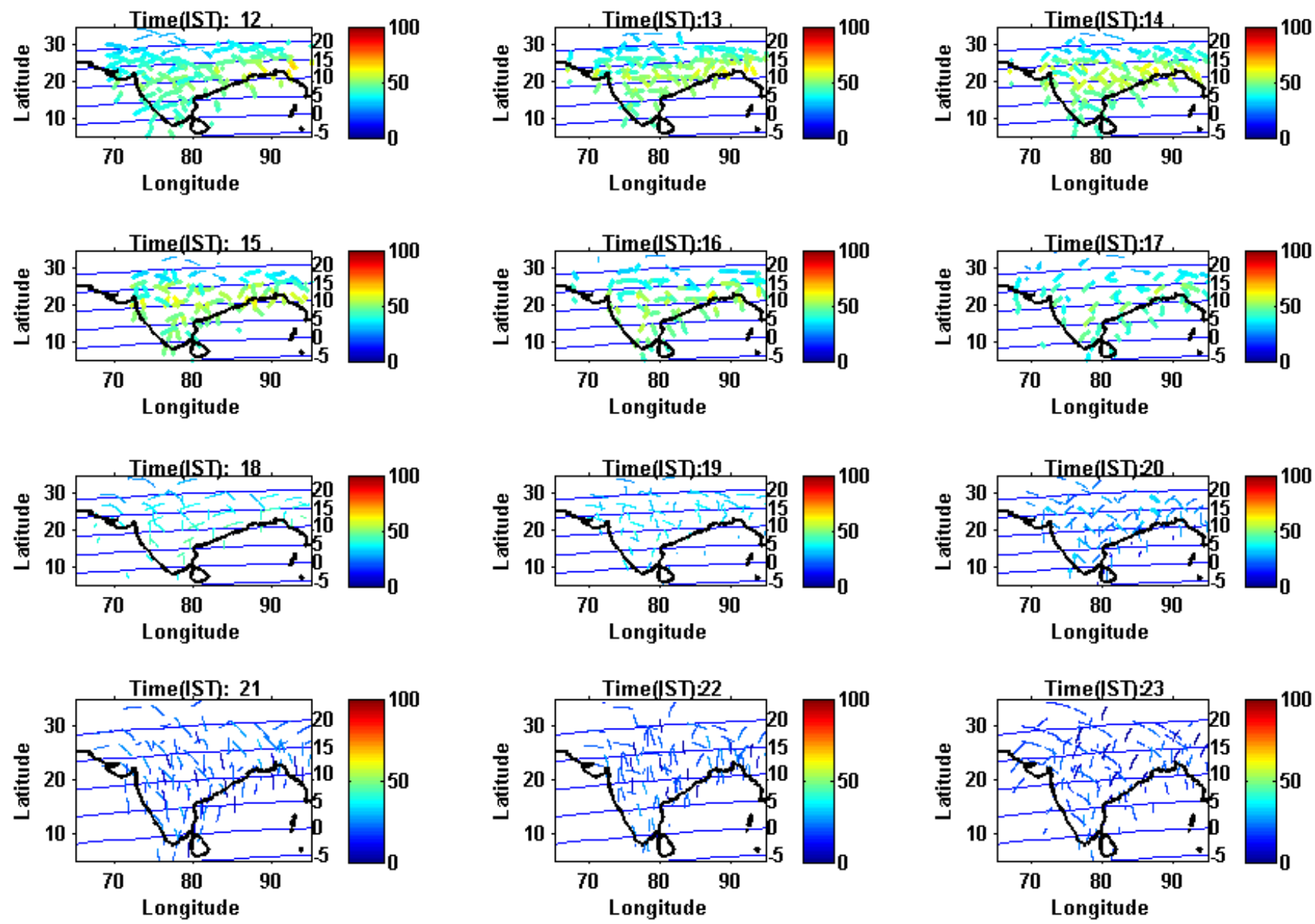

Fig. 13. The VTEC plotted on 27-28 May 2004 starting from 12:00 IST to 23:00 IST for every one hour. Here the y-axis on the right side represents the geomagnetic latitude.

Now, we shall consider here the TEC data plotted for 3 cases to understand further about the physical concept. It may be noted that in case- 1 and case- 2 , the observations over TRV suggest that the temporal variation of TEC is found to be mostly quite similar though there are certain differences. In the initial time of observations, when radar observations show $\sim 3 \mathrm{~m}$ scale irregularities, the large scale TEC depletions are also noted. The minimum TEC over TRV in case1 is less than that in other two cases indicating the role of strong density depletions during the time of ESF in case1. It may be noted that since this day is also magnetically somewhat active, the eastward electric field due to prompt penetration could have enhanced the $\boldsymbol{E} \times \boldsymbol{B}$ drift and hence leading to the minimum TEC over equator. The slope of the decrease in TEC in the initial phase of ESF in case-1 is much more rapid than that of case-2. In the post midnight sector, however, TEC interestingly increased for nearly one hour before it gradually decreased in both case- 1 and case- 2 .
The TEC maps also suggest that TEC enhancement is slowly moving towards equatorward for these two cases. But, such an increase in TEC is not seen over TRV in the case- 3 during post-midnight. This can be understood through the PRE of the $\boldsymbol{E} \times \boldsymbol{B}$ drift of the F layer and also through meridional wind circulation. In the first two cases, the PRE is found to be high (as suggested through ionosonde) and hence, due to PRE, F layer is lifted to higher altitudes during pre-midnight and then plasma is descended to the higher latitudes through plasma diffusion along the magnetic field lines. However, in the post-midnight sector, the ionization which is accumulated at higher latitudes could again be pushed to the lower latitudes through the reverse fountain effect as reported by Muella et al. (2008). This could lead to the enhancement in TEC at equatorial station as observed in our first two cases. But in the case-3, since there was no PRE observed in the ionosonde observations and hence the plasma irregularities are associated with fossil bubbles, post-midnight 

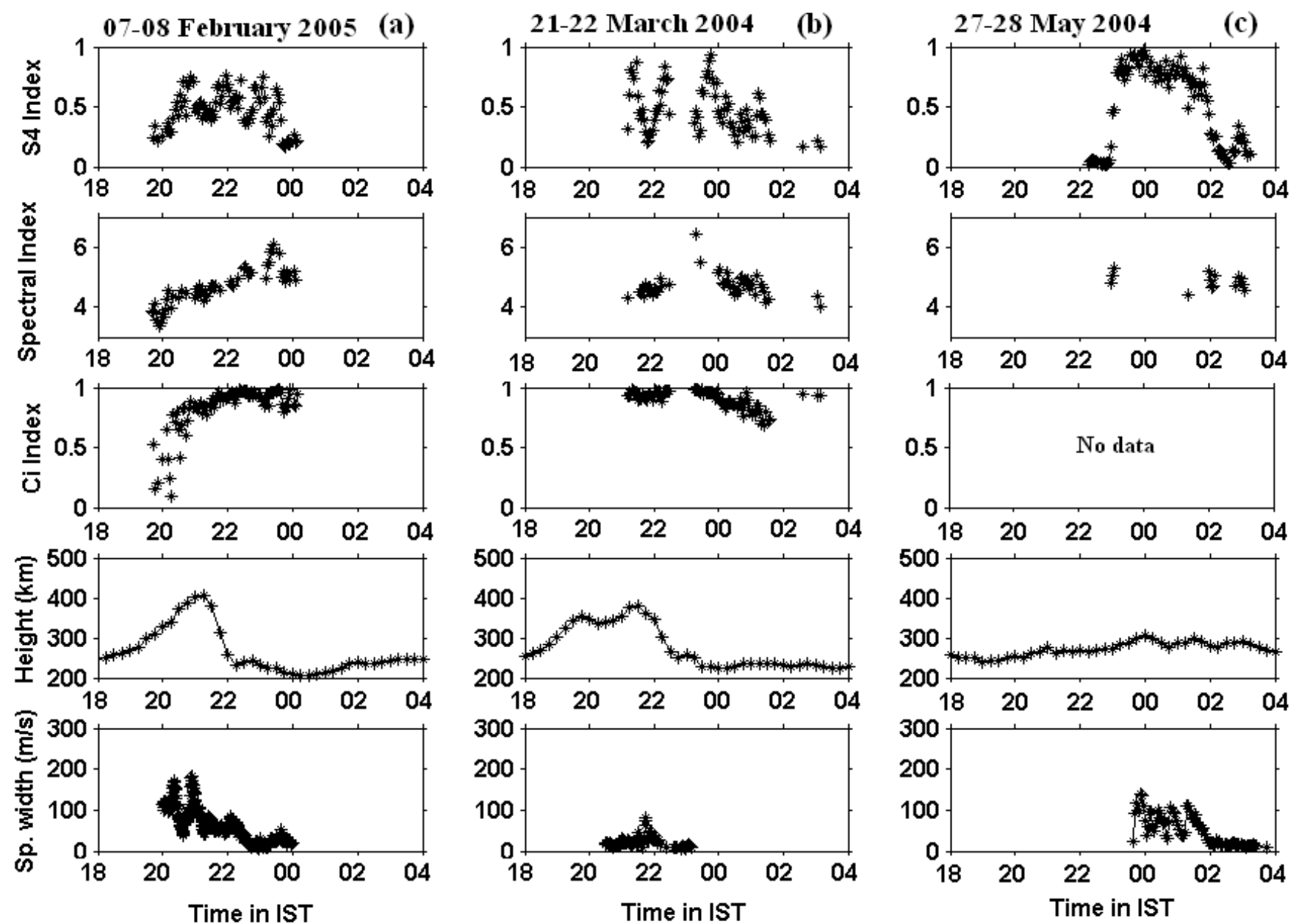

Fig. 14. Panels (a-c) contain five panels each representing $S_{4}$ index, spectral index (m), cross-correlation index (Ci), $h^{\prime} F$ and average spectral width, respectively, on 7-8 February 2005, 21-22 March 2004 and 27-28 May 2004.

enhancement in TEC is not seen because there was no accumulation of ionization at higher latitudes earlier.

The question that still remains is why L-band scintillations are not observed on this night although radar is able to detect $\sim 3 \mathrm{~m}$ scale irregularities. The answer lies in the scale size of the irregularities that produce radar echoes, L-band scintillations and VHF scintillations. In the decay phase of the irregularities, the small scale irregularities would decay first and only $\sim \mathrm{km}$ scale size irregularities would be able to focus the VHF signal which enhances the $S_{4}$ index at VHF (e.g. Bhattacharyya et al., 2003). But since few hundred meter irregularities have decreased, this leads to the weakening of L-band scintillations at this stage. However, the $\sim 3 \mathrm{~m}$ scale size irregularities which radar observes can not be generated directly through the R-T instability process. They are generated through other instabilities such as the drift-wave instability. The gradients due to kilometer scale structures could produce several secondary wave modes. This could lead to the generation of $\sim 3 \mathrm{~m}$ scale waves for which radar is sensitive. Hence the reason for the absence of L-band scintilla- tions is that $\sim 370-400 \mathrm{~m}$ scale size irregularities which are produced by R-T instability itself might not have sufficient strength to produce observable scintillations on L-band.

\section{Summary and conclusion}

The simultaneous observations of radar and GPS presented above reveal that a good correlation exists between radar echoes and GPS scintillations only when the plume type echoes reach higher altitudes in the pre-midnight sector. Here, the latitudinal distribution of L-band scintillations shows that the strength of $S_{4}$ index maximizes at about $22^{\circ} \mathrm{N}$ latitude. The GPS observations also suggest that both bottom type and post midnight irregularities do not give rise to significant L-band scintillations. A new observation is related to the detection of dead bubble in the post-midnight hours. Absence of L-band scintillations during post-midnight sector indicates the decay of irregularities of scale sizes of a few hundred meters. At the same time small scale $(\sim 3 \mathrm{~m})$ 
irregularities could have been generated through secondary waves on the walls of $\mathrm{km}$ scale size irregularities associated with a fossil bubble which produce VHF but not L-band scintillations; and these $3 \mathrm{~m}$ scale irregularities gave rise to radar echoes, although L-band scintillations were absent.

Acknowledgements. The research work presented here were carried out under the Indian Space Research Organization (ISRO), Govt. of India sponsored project, GAGAN. The authors are thankful to K. Bandopadhyay and M. R. Sivaraman, Space Application Centre, ISRO, Ahmedabad and their technical staff for providing the GAGAN data. Similarly, Indian MST radar data is obtained from National Atmospheric Research Laboratory (NARL) which is operated as an autonomous facility under Department of Space, Government of India. The authors are grateful to the EGRL (IIG) and NARL technical staff whose dedicated efforts made possible the observations presented here.

Topical Editor U.-P. Hoppe thanks E. de Paula and another anonymous referee for their help in evaluating this paper.

\section{References}

Abdu, M. A.: Outstanding problems in the equatorial ionospherethermosphere electrodynamics relevant to spread F, J. Atmos. Solar Terr. Phys., 63, 869-884, 2001.

Basu, S., Kudeki, E., Basu, S., Valladares, C. E., Weber, E. J., Zengingonul, H. P., Bhattacharyya, S., Sheehan, R., Meriwether, J. W., Biondi, M. A., Kuenzler, H., and Espinoza, J.: Scintillations, plasma drifts, and neutral winds in the equatorial ionosphere after sunset, J. Geophys. Res., 101(A12), 26795-26810, doi:10.1029/96JA00760, 1996.

Basu, Su. and Kelley, M. C.: Review of equatorial scintillations phenomena in light of recent developments in the theory and measurement of equatorial irregularities, J. Atmos. Terr. Phys., 39, 1229-1242, 1977.

Bhattacharyya, A., Franke, S. J., and Yeh, K. C.: Characteristic velocity of equatorial $\mathrm{F}$ region irregularities determined from spaced receiver scintillation data, J. Geophys. Res., 94(A9), 11 959-11 969, doi:10.1029/89JA00715, 1989.

Bhattacharyya, A., Beach, T. L., Basu, S., and Kintner, P. M.: Nighttime equatorial ionosphere: GPS scintillations and differential carrier phase fluctuations, Radio Sci., 35(1), 209-224, doi:10.1029/1999RS002213, 2000.

Bhattacharyya, A., Basu, S., Groves, K. M., Valladares, C. E., and Sheehan, R.: Dynamics of equatorial F region irregularities from spaced receiver scintillation observations, Geophys. Res. Lett., 28(1), 119-122, doi:10.1029/2000GL012288, 2001.

Bhattacharyya, A., Basu, S., Groves, K. M., Valladares, C. E., and Sheehan, R.: Effect of magnetic activity on the dynamics of equatorial F region irregularities, J. Geophys. Res., 107(A12), 1489, doi:10.1029/2002JA009644, 2002.

Bhattacharyya, A., Groves, K. M., Basu, S., Kuunzler, H., Valladares, C. E., and Sheehan, R.: L-band scintillation activity and space-time structure of low-latitude UHF scintillations, Radio Sci., 38(1), 1004, doi:10.1029/2002RS002711, 2003.

Bhattacharyya, A.: Role of $\mathrm{E}$ region conductivity in the development of equatorial ionospheric plasma bubbles, Geophys. Res. Lett., 31, L06806, doi:10.1029/2003GL018960, 2004.
Booker, H. G. and Wells, H. W.: Scattering of radio waves by the F-region of the ionosphere, J. Geophys. Res., 43, 249-256, 1938.

Burke, W. J., Gentile, L. C., Huang, C. Y., Valladares, C. E., and $\mathrm{Su}, \mathrm{S}$. Y.: Longitudinal variability of equatorial plasma bubbles observed by DMSP and ROCSAT-1, J. Geophys. Res., 109, A12301, doi:10.1029/2004JA010583, 2004.

de Paula, E. R., Iyer, K. N., Hysell, D. L., Rodrigues, F. S., Kherani, E. A., Jardim, A. C., Rezende, L. F. C., Dutra, S. G., and Trivedi, N. B.: Multi-technique investigations of storm-time ionospheric irregularities over the São Luís equatorial station in Brazil, Ann. Geophys., 22, 3513-3522, 2004,

http://www.ann-geophys.net/22/3513/2004/.

Devasia, C. V., Jyoti, N., Subbarao, K. S. V., Viswanathan, K. S., Tiwari, D., and Sridharan, R.: On the plausible linkage of thermospheric meridional winds with the equatorial spread F, J. Atmos. Solar Terr. Phys., 64, 1-12, 2002.

Farley, D. T., Balsley, B. B., Woodman, R. F., and McClure, J. P.: Equatorial spread F: Implications of VHF radar observations, J. Geophys., Res., 75, 7199-7216, 1970.

Fejer, B. G., Scherliess, L., and de Paula, E. R.: Effects of the vertical plasma drift velocity on the generation and evolution of equatorial spread F, J. Geophys. Res., 104, 19 859-19869, 1999.

Fejer, B. G. and Kelley, M. C.: Ionospheric irregularities, Rev. Geophys. Space Phys., 18, 401-454, 1980.

Haerendel, G.: Theory of equatorial spread F, unpublished report, Max Plank Institut fur Physik und astrophysik, Graching, Germany, 1974.

Hysell, D. L. and Burcham, J.: JULIA radar studies of equatorial spread F, J. Geophys. Res., 103, 29 155-29 167, 1998.

Immel T. J., Sagawa, E., England, S. L., Henderson, S. B., Hagan, M. E., Mende, S. B., Frey, H. U., Swenson, C. M., and Paxton, L. J.: Control of equatorial ionospheric morphology by atmospheric tides, Geophys. Res. Lett., 33, L15108, doi:10.1029/2006GL026161, 2006.

Kakad, B., Jeeva, K., Nair, K. U., and Bhattacharyya, A.: Magnetic activity linked generation of nighttime equatorial spread F irregularities, J. Geophys. Res., 112, A07311, doi:10.1029/2006JA012021, 2007.

Kelley, M. C., LaBelle, J., Kudeki, E., et al.: The Condor equatorial spread F campaign: Overview and results of the large-scale measurements, J. Geophys. Res., 91, 5487-5503, 1986.

Kelley, M. C., Hysell, D., and Musman, S.: Simultaneous Global Positioning System and radar observations of equatorial spread F at Kwajalein, J. Geophys. Res., 101(A2), 2333-2342, doi:10.1029/95JA02025, 1996.

Kelley, M. C.: The earth's ionosphere: Plasma physics and electrodynamics, Academic Press, San Diego, Calif., 113-182, 1989.

Keskinen, M. J., Ossakow, S. L., and Fejer, B. G.: Threedimensional nonlinear evolution of equatorial ionospheric spread-F bubbles, Geophys. Res. Lett., 30(16), 1855 , doi:10.1029/2003GL017418, 2003.

Kill, H. and Heelis, R. A.: Global distribution of irregularities in the equatorial ionosphere, J. Geophys. Res., 103, 407-417, 1998.

Kudeki, E. and Bhattacharyya, S.: Post-sunset vortex in equatorial $F$-region plasma drifts and implications for bottomside spread$F$, J. Geophys. Res., 104, 28 163-28 170, 1999.

Lee, C.-C., Liu, J.-Y., Reinisch, B.W., Chen, W.-S., and Chu, F.D.: The effects of the pre-reversal drift, the EIA asymmetry, and magnetic activity on the equatorial spread $\mathrm{F}$ during solar maxi- 
mum, Ann. Geophys., 23, 745-751, 2005,

http://www.ann-geophys.net/23/745/2005/.

Mendillo, M. and Baumgardner, J.: Airglow Characteristics of Equatorial Plasma Depletions, J. Geophys. Res., 87(A9), 76417652, 1982.

Muella, M. T. A. H., de Paula, E. R., and Kantor, I. J.: GPS L-band scintillations and ionospheric irregularity zonal drifts inferred at equatorial and low-latitude regions. J. Atmos. Terr. Phys., 70, 1261-1272, doi:10.1016/j.jastp.2008.03.013, 2008.

Niranjan, K., Brahmanandam, P. S., Ramakrishna Rao, P., Uma, G., Prasad, D. S. V. V. D., and Rama Rao, P. V. S.: Post midnight spread-F occurrence over Waltair $\left(17.7^{\circ} \mathrm{N}, 83.3^{\circ} \mathrm{E}\right)$ during low and ascending phases of solar activity, Ann. Geophys., 21, 745750,2003 ,

http://www.ann-geophys.net/21/745/2003/.

Ossakow, S. L.: Spread F theories - A review, J. Atmos. Terr. Phys., 43, 437-452, 1981.

Patra, A. K., Tiwari, D., Sripathi, S., Rao, P. B., Sridharan, R., Devasia, C. V., Viswanathan, K. S., Subbarao, K. S. V., Sekar, R., and Kherani, E. A.: Simultaneous radar observations of meter-scale F region irregularities at and off the magnetic equator over India, J. Geophys. Res., 110, A02307, doi:10.1029/2004JA010565, 2005.

Patra, A. K., Rao, P. B., Anandan, V. K., and Jain, A. R.: Radar observations of $2.8 \mathrm{~m}$ equatorial spread F irregularities, J. Atmos. Terr. Phys., 59, 1633-1644, 1997.

Raghavarao, R., Nageswararao, M., Sastri, J. H., Vyas, G. D., and Sriramarao, M.: Role of equatorial ionization anomaly in the initiation of equatorial spread F, J. Geophys. Res., 93, 5959-5964, 1988.

Rama Rao, P. V. S., Gopi Krishna, S., Niranjan, K., and Prasad, D. S. V. V. D.: Study of spatial and temporal characteristics of Lband scintillations over the Indian low-latitude region and their possible effects on GPS navigation, Ann. Geophys., 24, 15671580, 2006a,

http://www.ann-geophys.net/24/1567/2006/.

Rama Rao, P. V. S., Gopi Krishna, S., Niranjan, K., and Prasad, D. S. V. V. D.: Temporal and spatial variations in TEC using simultaneous measurements from the Indian GPS network of receivers during the low solar activity period of 2004-2005, Ann. Geophys., 24, 3279-3292, 2006b, http://www.ann-geophys.net/24/3279/2006/.

Rao, P. B., Jain, A. R., Kishore, P., Balamuralidhar, P., Damle, S. H., and Viswanathan, G.: Indian MST radar, 1, System description and sample vector wind measurements in ST mode, Radio Sci., 30, 1125-1138, 1995.

Rodrigues, F. S., de Paula, E. R., Abdu, M. A., Jardim, A. C., Iyer, K. N., Kintner, P. M., and Hysell, D. L.: Equatorial spread F irregularity characteristics over Sao Luis, Brazil, using VHF radar and GPS scintillation techniques, Radio Sci., 39, RS1S31, doi:10.1029/2002RS002826, 2004.
Sinha, H. S. S., Raizada, S., and Mishra, R. N.: First simultaneous in situ measurement of electron density and electric field fluctuations during spread $\mathrm{F}$ in the Indian zone, Geophys. Res. Lett., 20, 1669-1672, 1999.

Sultan, P. J.: Linear theory and modeling of the Rayleigh-Taylor instability leading to the occurrence of equatorial spread F, J. Geophys. Res., 101, 26 875-26891, 1996.

Thampi, S. V., Ravindran, S., Pant, T. K., Devasia, C. V., Sreelatha, P., and Sridharan, R.: Deterministic prediction of post-sunset ESF based on the strength and asymmetry of EIA from ground based TEC measurements: Preliminary results, Geophys. Res. Lett., 33, L13103, doi:10.1029/2006GL026376, 2006.

Tiwari, D., Engavale, B., Bhattacharyya, A., Devasia, C. V., Pant, T. K., and Sridharan, R.: Simultaneous radar and spaced receiver VHF scintillation observations of ESF irregularities, Ann. Geophys., 24, 1419-1427, 2006, http://www.ann-geophys.net/24/1419/2006/.

Valladares, C. E., Sheehan, R., Basu, S., Kuenzler, H., and Espinoza, J.: The multi-instrumented studies of equatorial thermosphere aeronomy scintillation system: Climatology of zonal drifts, J. Geophys. Res., 101(A12), 26 839-26850, doi:10.1029/96JA00183, 1996.

Valladares, C. E., Basu, S., Groves, K., Hagan, M. P., Hysell, D., Mazzella Jr., A. J., and Sheehan, R. E.: Measurement of the latitudinal distribution of total electron content during equatorial spread-F events, J. Geophys. Res., 106, 29 133-29 152, 2001.

Valladares, C. E., Villalobos, J., Sheehan, R., and Hagan, M. P.: Latitudinal extension of low-latitude scintillations measured with a network of GPS receivers, Ann. Geophys., 22, 3155-3175, 2004, http://www.ann-geophys.net/22/3155/2004/.

Van Dierendonck, A. J., Fenton, P., and Klobuchar, J.: Commercial ionospheric scintillation monitoring receiver development and test results, Proceedings of the Institute of Navigation's 52nd Annual Technical Meeting, Cambridge, MA, 573-582, 1996.

Whalen, J. A.: The equatorial anomaly: Its quantitative relation to equatorial bubbles, bottomside spread F, and $\boldsymbol{E} \times \boldsymbol{B}$ drift velocity during a month at solar maximum, J. Geophys. Res., 106(A12), 29 125-29 132, doi:10.1029/2001JA000089, 2001.

Whalen, J. A.: Dependence of equatorial bubbles and bottomside spread $\mathrm{F}$ on season, magnetic activity, and $\boldsymbol{E} \times \boldsymbol{B}$ drift velocity during solar maximum, J. Geophys. Res., 107(A2), SIA 3-1-9, doi:10.1029/2001JA000039, 2002.

Yeh, K. C. and Liu, C. H.: Radio wave scintillations in the ionosphere, Proc. IEEE, 70(4), 325-378, 1982. 